\title{
Development of a Modular Draping Test Bench for Analysis of Infiltrated Woven Fabrics in Wet Compression Molding
}

\author{
Fabian Albrecht ${ }^{1,2, a^{*}}$, Clemens Zimmerling ${ }^{1, b}$, Christian Poppe ${ }^{1, c}$, \\ Luise Kärger ${ }^{1}$ and Frank Henning ${ }^{1,2}$
}

\begin{abstract}
${ }^{1}$ Karlsruhe Institute of Technology (KIT), Institute of Vehicle Systems Technology (FAST), Chair for Lightweight Technology, Rintheimer Queralle 2, Bldg. 70.04, 76131 Karlsruhe, Germany

${ }^{2}$ Fraunhofer Institute for Chemical Technology (ICT), Department of Polymer Engineering, Josephvon-Fraunhofer-Strasse 7, 76327 Pfinztal, Germany

afabian.albrecht2@kit.edu, bclemens.zimmerling@kit.edu, christian.poppe@kit.edu

*corresponding author
\end{abstract}

Keywords: Wet compression molding (WCM), Textile Testing, Viscous Draping, Forming, Woven Fabrics

\begin{abstract}
The wet compression molding (WCM) process enables short cycle times for production of fiber-reinforced plastics due to simultaneous infiltration, viscous draping and consolidation in one process st ep. This requires a co mprehensive k nowledge of occurring $\mathrm{m}$ utual dependencies i $\mathrm{n}$ particular for the development of process simulation methods and for process optimization. In this context, it is necessary to develop suitable test benches to enable an evaluation of the outlined viscous draping behavior. In order to evaluate and suitably design the draping process, grippers are mounted on a surrounding frame, which enables targeted restraining of the local material d raw-in during forming. In s upporting the de velopment of the new test be nch, first experimental and s imulation results are compared, which thereby enables a first validation of the simulation approaches. Results show a g ood agreement between experimental and numerical results in terms of s hear d eformation and final gripper d isplacement under dry and viscous conditions. R esults r ecommend that future development for investigations of viscous draping effects should focus an enabling measurement of gripper displacement during the forming process. Beyond that, the modular test bench design enables experimental and virtual dr aping o ptimization and de duction of bl ank holder concepts for WCM tools.
\end{abstract}

\section{Introduction and State of the Art}

The WCM process is a promising option for the serial production of fiber-reinforced plastics with a thermoset matrix [1-3]. the WCM p rocess w ith s imultaneous fiber forming and press process (4), starting from cutting and stacking of the fibers (1) to the demolding of the final part (5).

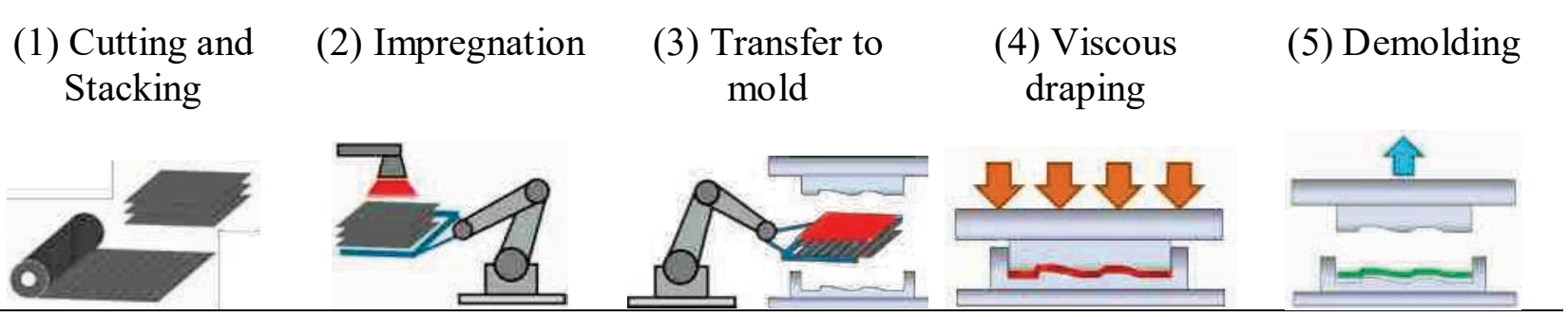

Figure 1: Schematic process steps of the Wet Compression Molding process (according to [4, 5]).

In contrast to the widely used Resin Transfer Molding (RTM) process, in which the pre-shaped dry preform is impregnated inside the press during an injection step, the impregnation in the WCM process takes place outside of the press (2). After the transport (3), the dry two-dimensional la yers are formed into the three-dimensional part geometry in the actual press step (4). The forming of the textile thus takes place in an impregnated state (viscous draping). The number of publications in the 
field of $\mathrm{WCM}$ process is cu rrently low. P revious investigations mainly evaluate the influence of process $\mathrm{p}$ arameters o $\mathrm{n}$ the finished $\mathrm{p}$ art. Interrelations between $\mathrm{p}$ rocess b oundary conditions a nd surface characteristics (e.g. folds and dry spots) [2], the difference between varied designs of wall thickness transitions [3] as well as the influence of closing speed, resin temperature and infiltration time on resin expansion within a cavity [6] are investigated. Beyond that, Heudorfer et al. [7] show an influence of resin amount and infiltration time on the mechanical performance of the final parts. Similar to the geometry in the present study, Kahn et al. [8] developed an experimental Double Dome forming $\mathrm{t}$ ool to $\mathrm{v}$ alidate their numerical forming $\mathrm{s}$ imulation a pproach. First $\mathrm{i}$ nvestigations o $\mathrm{n}$ dependencies of the infiltration state show differences between dry and wet interlaminar friction [4]. The impact of infiltration on the shear behavior of infiltrated woven fabrics is demonstrated by Poppe et al . [ 5] b y means o f a modified b ias e xtension test (IB ET). Beyond t hat, FE-based forming simulations are performed to access the process relevance of infiltration-dependent shear behavior. The predicted numerical results indicate an important impact of the infiltration on the shear angle distribution during draping. However, the interactions resulting from a wet forming process have not yet been researched experimentally. In order to evaluate and suitably design the draping process in the infiltrated and dry state, 48 grippers are mounted on a surrounding frame (clamping frame) which in t urn e nables introducing and possible recording of the restraining local material draw-in while forming. Moreover, the $\mathrm{n}$ ew $\mathrm{t}$ est $\mathrm{b}$ ench facilitates a suitable $\mathrm{v}$ alidation of the viscous forming behavior for the development of process simulation methods [5,9].

In this study, first viscous forming tests are performed with the clamping frame, which so far enables determination of the final material draw-in. Additionally, an optical evaluation method is presented to determine the local s hear angle a fter forming. Subsequently, a first va lidation of the nu merical model published by Poppe et al. [5] is presented, which indicates further promising enhancements for the new test bench. Prospectively, the test bench's modular design enables performance assessments of different blank holder concepts for optimization of forming results. These identified concepts can in turn be used to develop clamping concepts for press tools on a large series scale.

\section{Experimental Set-Up and Trial Execution}

Test bench set-up. For this study, a modular draping station as seen in Figure 2 (a) is developed. This d raping station consists of an aluminum table and a base frame. On the table, the developed clamping frame can be transferred between the 'forming' position $u$ nder the $b$ ase frame a nd the 'loading' platform outside the base frame. The clamping frame is shown in Figure 2 (b). It contains 48 grippers arranged in a rectangle, on separate slide rails.

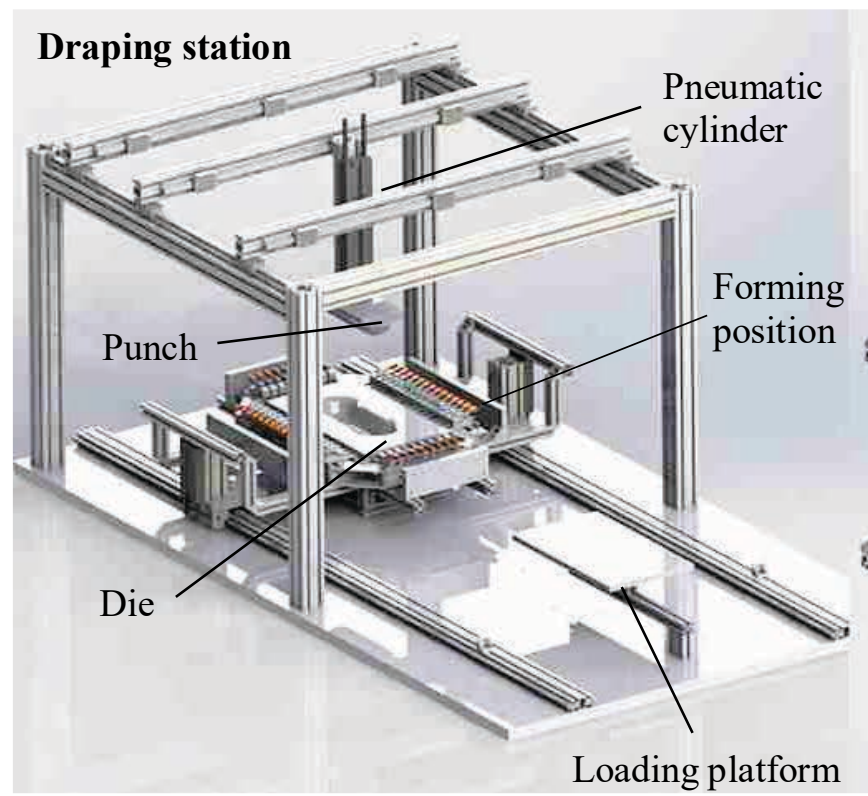

(a)

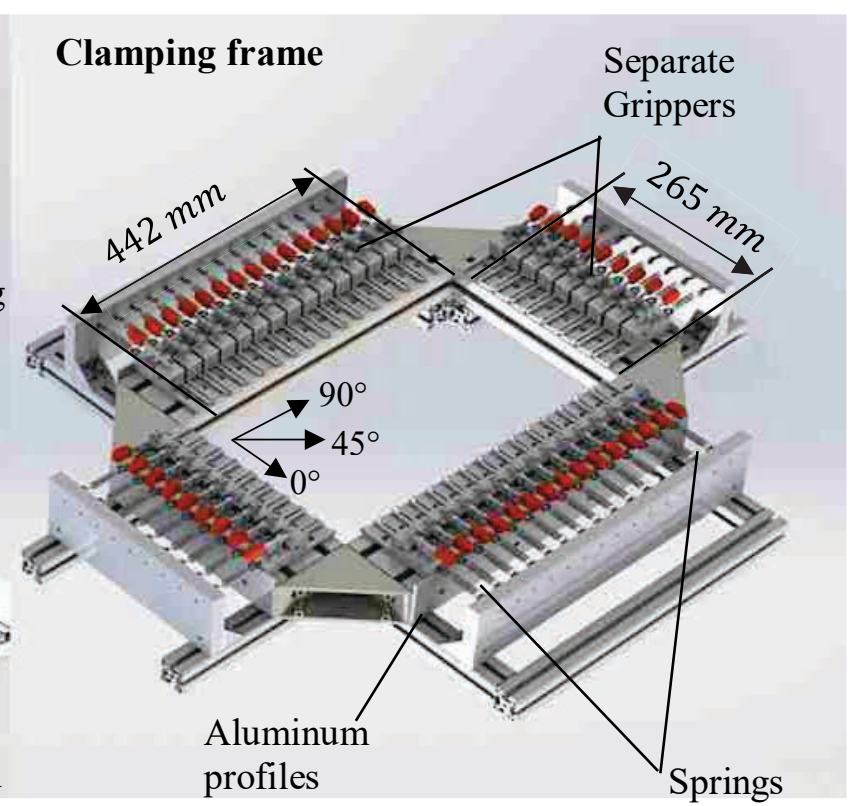

(b)

Figure 2: Modular draping station (a) and clamping frame including 48 separate grippers (b). 
The design of the grippers enables slight vertical rotation. The kinematic of the grippers is shown in Figure 3 (a). The restraining forces of the grippers are induced by exchangeable springs. A generic Double Dome geometry is used in this study. For the movement of the punch, a pneumatic cylinder from Festo AG \& Co. KG is used. The pneumatic cylinder is connected to the punch via an adapter plate and mounted on the recirculating linear rail guide of a traverse via an aluminium profile. The stroke of $400 \mathrm{~mm}$ enables good accessibility to the clamping frame in the forming position.

Material and trial execution. The study examined a carbon fiber plain woven fabric with a filament yarn c onsisting of T 700-12K-50C T oray fibers a nd a basis weight of $300 \pm(10) \mathrm{g} / \mathrm{mm}^{2}$ from Sigmatex (GB). The roving width is $5.0 \pm 0.5 \mathrm{~mm}$ with initial spaces of $2.0 \pm 0.3 \mathrm{~mm}$. The semifinished fiber product, $w$ hich is $\mathrm{s}$ upplied a s a fiber $\mathrm{r}$ oll, $\mathrm{w}$ as $\mathrm{c}$ ut to $\mathrm{m}$ atch $\mathrm{t}$ he $\mathrm{c}$ lamping frame dimensions $(770 \times 570 \mathrm{~mm} 2)$ and the desired fiber o rientation $\left( \pm 45^{\circ}\right)$. A fter cutting, one ply is fixed in the clamping frame in 'loading' position. The clamping frame is then moved into the tool ('forming' position). Once in 'forming' position, silicone oil of defined viscosity is applied for fabric infiltration. After 30 seconds infiltration time, the punch is pneumatically actuated. As soon as the punch has completely formed the fabric, the traversed distance $\Delta l$ (fiber feed, cf. Figure 3 (left)) of the $\mathrm{i}$ ndividual $\mathrm{g}$ rippers is $\mathrm{r}$ ecorded. B efore $\mathrm{p}$ unch $\mathrm{r}$ etraction, $\mathrm{t}$ he $\mathrm{g}$ rippers ar e o pened $\mathrm{t} \mathrm{o}$ av oid inadmissible s pring-back of the textile. Validation of the forming result is based on the measured fiber feed $\Delta l$ and on o ptical investigation of the forming results (shear angle). For this purpose, a camera system is installed for photographic documentation of the fabric deformation state. Since the Double D ome is a do uble-symmetric g eometry, ca mera s hots ar e taken from only o ne side. An evaluation region is defined which covers the zone of highest shear deformation (cf. Figure 3 (right)). From this region, shear angles are extracted at 15 positions using an in-house written Matlab® tool. To account for the perspective distortion, a geometric correction factor is used for post-processing. For the ex ecution of the w et forming trials, three $d$ ifferent infiltration $s$ tates are investigated. In addition to the dry state, silicone oils with viscosities of $20 \mathrm{mPas}$ and $250 \mathrm{mPa}$ are used as resin replacement $\mathrm{s}$ ystems $[4,5]$. To ev aluate the ef fect of the retention forces, two different $\mathrm{s}$ pring configurations are applied during the test. In the first constellation, weak springs with a stiffness of $R_{\text {weak }}=0.016 \mathrm{~N} / \mathrm{mm}$ are applied at all 48 gripper positions. The second configuration makes use of stronger springs $R_{\text {strong }}=0.48 \mathrm{~N} / \mathrm{mm}$ at all 48 grippers. As initial fiber orientation of the fabric $\pm 45^{\circ}$ is $\mathrm{u}$ sed. $\mathrm{T}$ he penetration $\mathrm{s}$ peed (approx. $60 \mathrm{~mm} / \mathrm{s}$ ), the penetration force of the $\mathrm{p}$ unch $(454 \mathrm{~N})$ a $\mathrm{s}$ well a s the quantity of the $r$ esin $r$ eplacement medium $(60 \mathrm{ml})$ are kept c onstant. I n order to $\mathrm{i}$ ncrease $\mathrm{t}$ he statistical s ignificance, each $t$ rial is $r$ epeated three times.

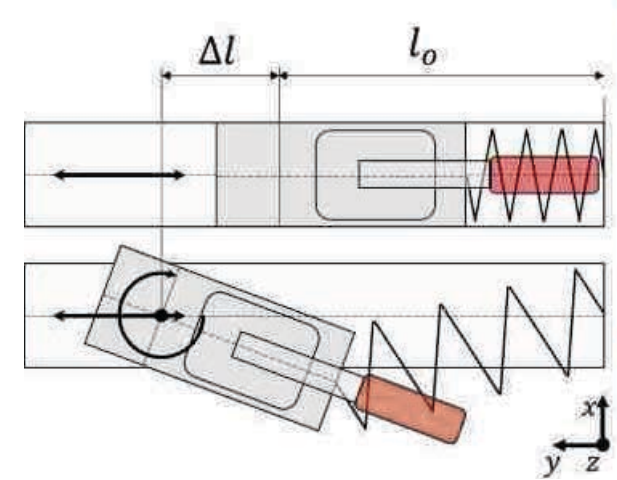

(a)

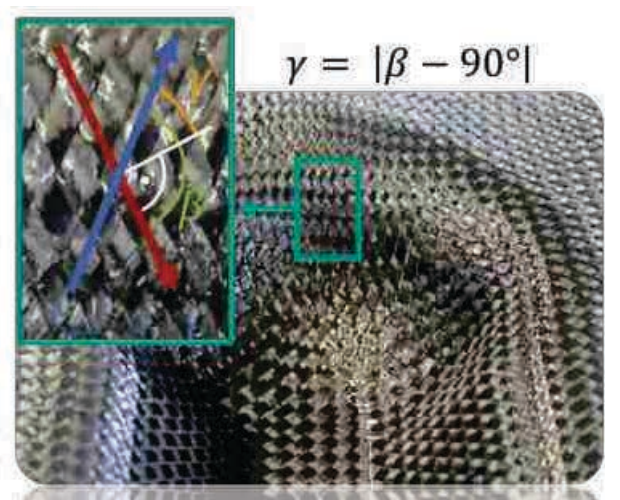

(b)

Figure 3: G ripper ki nematic and determination of the traverse position $\Delta l$ (a) a nd determination of the resulting shear angle $\gamma(\mathrm{b})$.

\section{Numerical Part.}

In the following, the applied macroscopic FE forming simulation approach is presented along with the virtual representation of the above outlined test bench including the Double Dome geometry and the modular clamping frame.

Numerical mo del. FE f orming s imulation is based o $\mathrm{nc}$ onstitutive modelling o $\mathrm{ft}$ he relevant interactions during forming. The forming mechanisms are normally categorized according to intraply and interface mechanisms [10]. Intra-ply mechanisms, namely membrane and bending behavior, 
are implemented by means of user subroutines within the commercially available FE solver ABAQUS. Membrane behavior is accounted for by a h yperviscoelastic material model parametrized with dry and infiltrated specimens v ia a modified (infiltrated) bias e xtension t est (IBET) [5]. Furthermore, bending behavior is implemented by means of a hypoviscoelastic constitutive model, which properly accounts for fiber reorientation during forming [10]. To model the decoupled membrane and bending behavior, superimposed membrane and shell elements are applied to represent the single layer of the stacked 1 aminate. An ABAQUS built-in c ontact $f$ ormulation is $u$ sed $t o$ acc ount for the $i$ nterface mechanisms between $\mathrm{t}$ ool and $\mathrm{p}$ ly. Constitutive models for i ntra-ply be havior in $\mathrm{t}$ his s tudy a re parametrized for the applied material as used in the experiment including the same viscosities for the fluid. A constant coefficient of friction $\boldsymbol{\mu}=\mathbf{0 . 2}$ is implemented for all simulations [4].

Simulation s etup. A $v$ irtual $r$ epresentation of $t$ he a bove o utlined $t$ est bench (cf. Figure 2 ) in conjunction with the introduced numerical model according to Figure 4 (a) is set up and applied in the following. F orming $\mathrm{s}$ imulations $\mathrm{w}$ ith $\mathrm{s}$ ingle $\mathrm{p}$ lies a re $\mathrm{c}$ onducted $\mathrm{w}$ ith a nd $\mathrm{w}$ ithout gr ippers. Whereas the tools are modelled as rigid surfaces, g rippers are imp lemented by means of suitable combinations of $\mathrm{k}$ inematic c onstrains, s prings (blue lin es) and b oundary co nditions acc ording to Figure 3 (a) and Figure 4 (a). Friction of the sleds is neglected in this first simulation approach. A constant closing speed of $60 \mathrm{~mm} / \mathrm{s}$ is applied to the upper tool by means of a linear displacement boundary c ondition. Gravity is taken into account. An explicit time integration schema is u sed to handle the large contact areas between tool and ply. Springs with equal stiffness are used in this first approach $\mathrm{f}$ or a $\mathrm{ll}$ gr ippers. E xploiting the double-symmetry ( geometry, grippers a nd fabric orientation), only a quarter model is implemented.

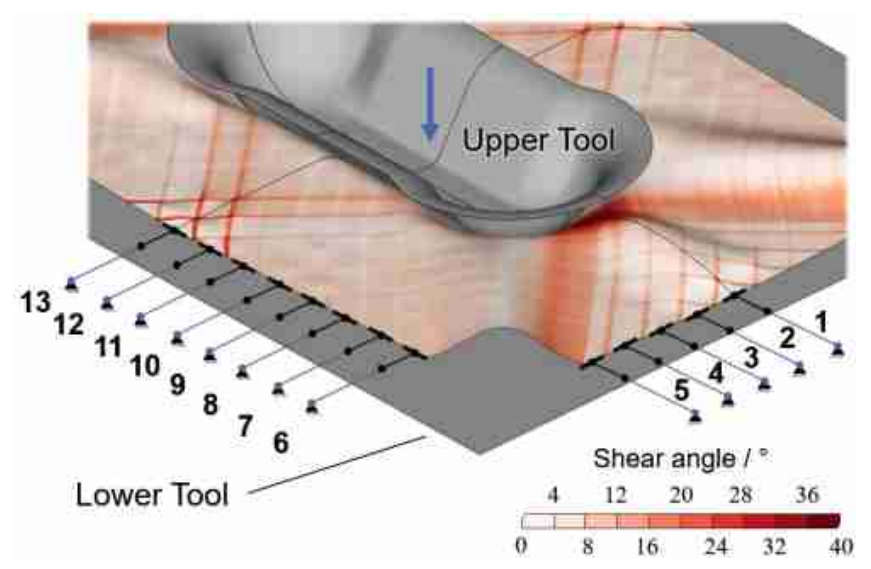

(a)

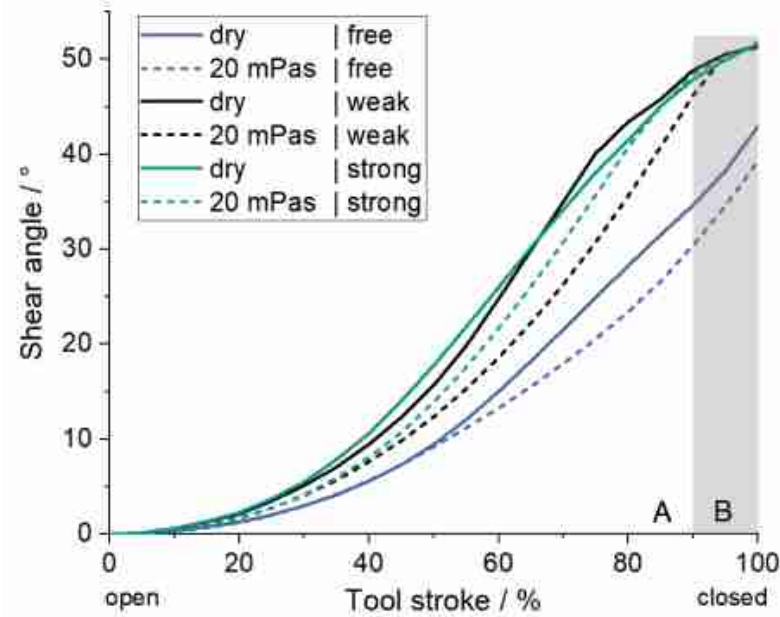

(b)

Figure 4: (a) Simulation model in ABAQUS comprising numbered gripper positions; (b) Simulation results: averaged shear angles in evaluation zone (cf. Fig. 3 (b)) during single ply forming simulations for three gripper configurations (free, weak springs, strong springs) and two infiltration states (dry, 20mPas) with initial fiber orientation of \pm 45 degree.

The numerical studies reveal that the effect of viscosity mainly concerns the shear angle distribution during forming, indicated by Region A in Figure 4 (b). The numerical setup without grippers (free), predicts an impact of viscosity on the shear angle distribution, even for the final shape (Region B). In contrast to that, numerical setups with grippers limit the impact to Region A. This seems reasonable in this case, since the final shape of the ply is almost only kinematically constrained, when grippers are present within the simulation. Therefore, in the course of test bench development, the final shape (Region B) enables a first evaluation of the overall design idea by comparison of experimental results among o ne an other an $d b$ etween ex perimental an $d s$ imulation $r$ esults $t o v$ alidate the $s$ imulation approach. 


\section{Comparison and Discussion of Experimental and Numerical Results}

Direct comparison of the experimental gripper displacements among the four symmetric zones of the test bench p rove reliability of the measured data. Thus, the experimental results are averaged with regard to the double symmetric setup. Furthermore, the experimental results show that the impact of infiltration on the final deformation state (cf. Region B, Figure 4 (b)) is negligible compared to the uncertainty of the measured shear angles (cf. Figure 5 (a)) similar to the prediction of the numerical model. Moreover, the comparison of the maximal measured shear angles within the evaluated main deformation zone provides a good agreement between experiment and simulation. Again, simulation provides systematically higher values. For improved c larity, values of all viscosities are a veraged within Figure 5 (b), where a comparison between the experimental and numerical results regarding the final gripper displacements is presented. Whereas the overall displacement profile shows a good agreement, simulation results are systematically higher than the experimental values. A systematic deviation is introduced by increasing gr ipper tensions, c omparably pr edicted by experiment a nd simulation. Furthermore, potential friction within the sleds could locally increase the gripper forces during the experiments, thus experimental displacements are systematically lower.

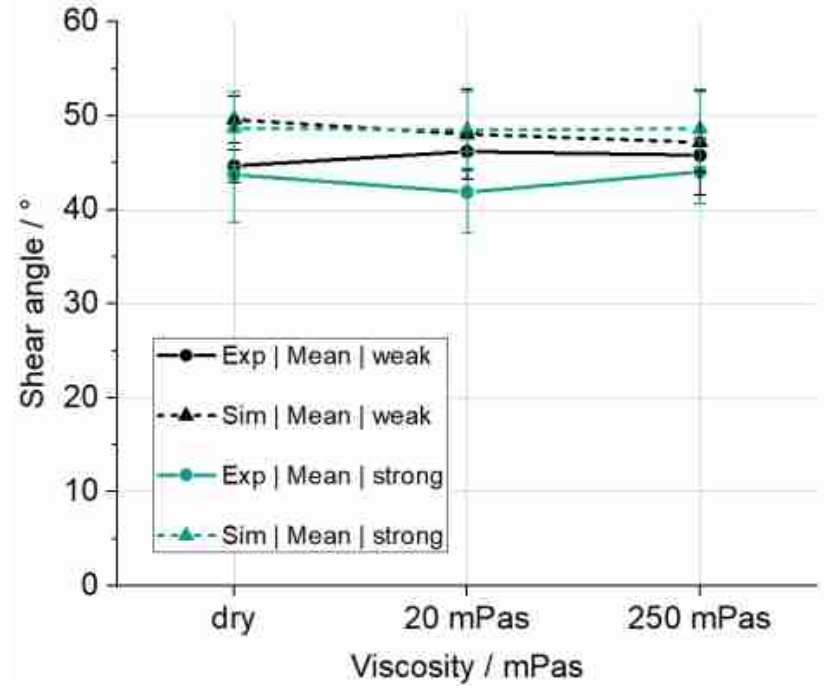

(a)

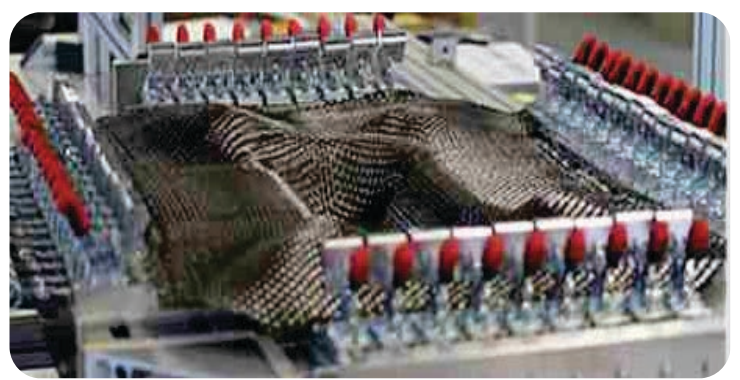

(c)

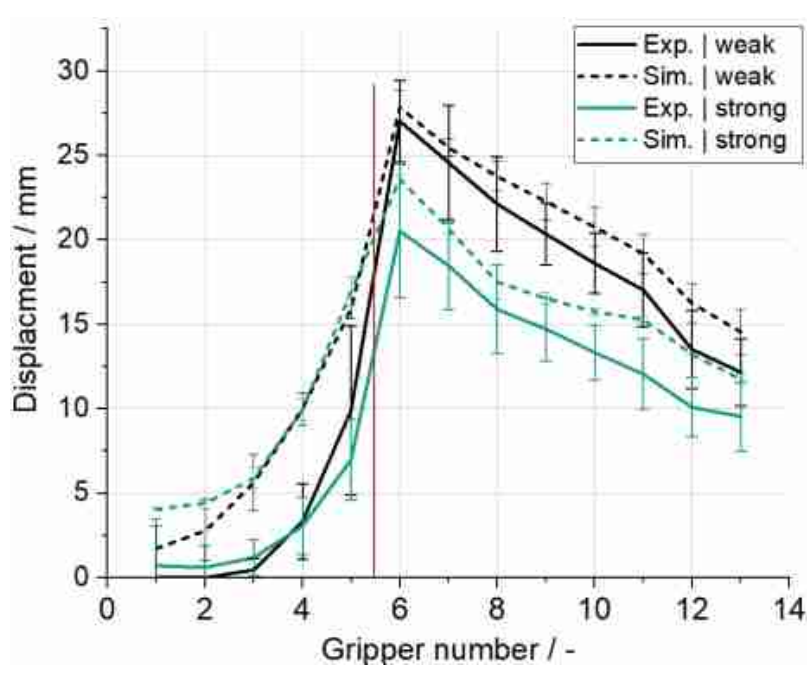

(b)

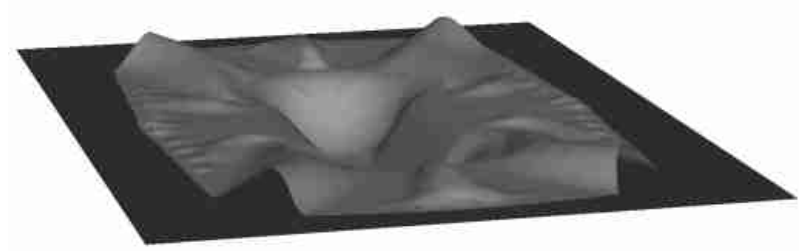

(d)

Figure 5: Comparison between experimental and numerical results of the formed woven fabric with initial fibre orientation of \pm 45 degree; (a) Impact of vi scosity on the final average shear angle (Region B); (b) Differences regarding the final gripper displacement profile for both spring stiffness's; (c,d) Comparison: experimental and numerical result of the overall shape.

Finally, the overall shape of the deformed parts in both experiment and simulation are co mparable according to Figure 5 (c, d). The outlined differences between e xperiment and simulation mainly origin from two effects. First, mesoscopic draping effects, namely relative slippage and wrinkling of the rovings, are observed to some degree during the experiments, but cannot be accounted for by the macroscopic approach. Second, friction within the sleds, which leads to increased gripper tensions, is neglected in the simulation. This leads to the prediction of increased local deformations (e.g. shear angles) compared to the experiments. 


\section{Conclusion and Outlook}

The present work introduces a modular draping test bench, which enables targeted restraining of the local material draw-in due to grippers mounted on a surrounding frame in wet compression molding (WCM). Initial experimental tests with d ry a nd infiltrated w oven fabrics prove $r$ eliability o f t he overall d esign. M oreover, first $\mathrm{v}$ irtual $t$ ests ar e in g ood ag reement $\mathrm{w}$ ith the ex perimental results. However, to enable a deeper investigation of the viscous draping behavior, further improvements have t o be implemented, in $\mathrm{p}$ articular inline measurement of $\mathrm{t}$ he $\mathrm{g}$ ripper $\mathrm{d}$ isplacements $\mathrm{d}$ uring forming and differently distributed stiffness of the gripper springs. Consequently, viscous forming behavior can be investigated along with the development and comparison of different blank holder systems a nd tool co ncepts in the $\mathrm{n}$ ear future. B eyond that, the modular d esign enables directed optimization and manipulation of di fferent $b$ lank holder s ystems for si ngle- and $m$ ulti-ply configurations, which will also be in scope of future efforts.

\section{Acknowledgment}

The authors thank the German State Ministry for Science, Research and Art of Baden-Württemberg (MWK) for the funding of the project Forschungsbrücke KIT - University Stuttgart, for which the presented work is carried out. Additionally, the authors would like to thank their project partners at Stuttgart University, Institute for Aircraft Design (IFB) under leadership of Prof. Middendorf for the collaboration. The w ork is also part of the Young Investigator Group ( YIG) "Tailored Composite Materials for Lightweight Vehicles”, generously funded by the Vector Stiftung.

\section{References}

[1] Henning F, K ärger L, D örr D , S chirmaier F J, S euffert J , B ernath A : F ast processing a nd continuous s imulation of a utomotive s tructural $\mathrm{c}$ omposite $\mathrm{c}$ omponents, Composites $\mathrm{S}$ cience a nd Technology 171: 261-279, 2019.

[2] Bergmann J, Dörmann H, Lange R: Interpreting process data of w et pressing process. Part 1: Theoretical approach, Part 2: Verication with real values. Journal of Composite Materials 50 ( 17): 2399-2407 \& 2409-2419, 2016.

[3] Stanglmaier, S. J.: Empirische Charakterisierung und Modellierung des Imprägnierprozesses lokal verstärkter $\mathrm{K}$ ohlenstofffaserhalbzeuge im R TM- und N asspress-Verfahren für d ie G roßserie. Karlsruhe, Karlsruher Institut für Technologie (KIT). Dissertation. 2017.

[4] Hüttl, J., Poppe, C., Albrecht, F., Lorenz, F., Thoma, B., Kärger, L., Middendorf P., Henning, F., "Investigations o $\mathrm{n}$ friction be haviour a nd forming $\mathrm{s}$ imulation of $\mathrm{pl}$ ain w oven fabrics for w et compression moulding", conference contribution, Proceedings S AMPE Europe, Stuttgart, Germany (2017)

[5] Poppe, C., Dörr, D., Henning, F., Kärger, L.: Experimental and numerical investigation of the shear $\mathrm{b}$ ehavior of infiltrated $\mathrm{w}$ oven $\mathrm{f}$ abrics, Composite $\mathrm{P}$ art $\mathrm{A}, \mathrm{V}$ ol 14, 327 -337, 2018 https://doi.org/10.1016/j.compositesa.2018.08.018

[6] Bockelmann, P.: Process Control in Compression Molding of Composites. München, Technische Universität München, Fakultät für Maschinenwesen, Lehrstuhl für Carbon Composites. Dissertation. 2017.

[7] Heudorfer, K., Carosella, C., Middendorf, P.: Compression Wet Moulding as alternative to RTM. 25. Stuttgarter Kunststoffkolloquium, Germany (2017)

[8] Khan, M. A., Mabrouki, T.; Vidal-Sallé, E., Boisse, P.: Numerical and experimental analyses of woven composite reinforcement forming using a hypoelastic behaviour. Application to the double dome benchmark. In: Journal of Materials Processing Technology 210 (2010), Nr. 2, S. 378-388

[9] Poppe C, Dominik D, Kärger L, Henning F, “A 2D modeling approach for fluid pr opagation during FE-forming simulation of continuously reinforced composites in wet compression molding" Proceedings of the ESAFORM2018, Palermo/Italy, 2018 10.1063/1.5034823

[10] Dörr, D., Schirmaier, F., Henning, F., Kärger, L., "A viscoelastic approach for modeling bending behavior in $\mathrm{f}$ inite element $\mathrm{f}$ orming $\mathrm{s}$ imulation o f co ntinuously fiber $\mathrm{r}$ einforced co mposites", Composites Part A, Vol. 94, pp. 113-123 doi:10.1016/j.compositesa.2016.11.027 (2017) 
Karlsruher Institut für Technologie

\section{Repository KITopen}

Dies ist ein Postprint/begutachtetes Manuskript.

Empfohlene Zitierung:

Albrecht, F.; Zimmerling, C.; Poppe, C.; Kärger, L.; Henning, F.

Development of a modular draping test bench for analysis of infiltrated woven fabrics in wet compression molding.

2019. Key engineering materials, 809

doi: $10.5445 / / R / 1000098668$

Zitierung der Originalveröffentlichung:

Albrecht, F.; Zimmerling, C.; Poppe, C.; Kärger, L.; Henning, F.

Development of a modular draping test bench for analysis of infiltrated woven fabrics in wet compression molding.

2019. Key engineering materials, 809, 35-40.

doi:10.4028/www.scientific.net/KEM.809.35 